\title{
Is Bikesharing Contagious? Modeling Its Effects on System Membership and General Population Cycling
}

\author{
Jessica Schoner, Greg Lindsey, and David Levinson
}

\begin{abstract}
Bikeshare systems are relatively new, highly visible additions to urban transportation systems that provide opportunities to cycle or combine cycling with other modes of transportation. The research reported here presents new evidence about the role of bikeshare systems in travel behavior on the basis of diffusion of innovation theory. The study hypothesized that bikeshare systems have spatial contagion or spillover effects on $(a)$ the propensity of individuals to adopt bikeshare and (b) the propensity to bicycle within the general population. The first hypothesis $(\mathrm{H} 1)$ was tested by modeling membership growth as a function of system expansion and the existing, proximate membership base. The second hypothesis $(\mathrm{H} 2)$ was tested by using bikeshare activity levels near home in a model of household-level bicycle participation and trip frequency. The study yielded mixed results. Bikeshare membership growth appeared to be driven in small part by a contagion effect of existing bikeshare members nearby, even after controlling for system growth. However, within the general population, a significant relationship was not identified between proximity to bikeshare stations and cycling participation or frequency. These findings complement those of other recent studies of bikeshare systems, which indicated that systems are still evolving. The present findings also have implications for marketing, infrastructure investments, and future research about bikeshare operations and innovation.
\end{abstract}

Bikeshare systems are relatively new, highly visible additions to urban transportation systems, which provide opportunities to cycle or combine cycling with other modes of transportation. With a diffusion of innovation framework, this paper presents new evidence about the role of bikeshare systems in travel behavior, including new models that estimate propensity to cycle and control for access to bikeshare. It was hypothesized that bikeshare systems have spatial contagion or spillover effects on (a) the propensity of individuals to adopt bikeshare (i.e., to join as a member), and $(b)$ the propensity to bicycle within the general population. The first hypothesis was tested by modeling membership growth as a function of system expansion and the existing membership base. The second hypothesis was tested by using bikeshare activity levels near home in a model of household-level bicycle participation and trip frequency.

J. Schoner and D. Levinson, Department of Civil, Environmental, and Geo-Engineering, College of Science and Engineering, 500 Pillsbury Drive Southeast, and G. Lindsey, Humphrey School of Public Affairs, 301 19th Avenue South, University of Minnesota, Twin Cities, Minneapolis, MN 55455. Corresponding author: J. Schoner, schon082@umn.edu.

Transportation Research Record: Journal of the Transportation Research Board, No. 2587, Transportation Research Board, Washington, D.C., 2016, pp. 125-132. DOI: 10.3141/2587-15
Data for the case study came from Nice Ride Minnesota, a bikeshare program implemented in the Twin Cities (i.e., Minneapolis and Saint Paul), Minnesota, in 2010, and from a 2011 travel behavior inventory conducted by the Metropolitan Council, the regional planning organization for the Twin Cities metropolitan area.

The study yielded mixed results and had implications for policy, practice, and research. After system growth was controlled for, it appeared that bikeshare membership growth was driven in small part by a contagion effect of existing, nearby bikeshare members. However, a significant relationship was not identified between proximity to bikeshare and cycling participation or frequency within the general population. Explanations for these findings may be multiple, including the fact that the role of bikeshare within the transportation system is still evolving.

This paper begins with brief reviews of the literature on diffusion of innovation and bikeshare systems. After the data and methodology are described, the findings are presented about how bikeshare influences, respectively, its own membership and the decisions of individuals within the general population to bicycle. The paper concludes with a discussion of the implications and limitations of the findings and opportunities for future research.

\section{LITERATURE REVIEW}

\section{Diffusion of Innovation Theory}

Diffusion of innovation theory emerged in the first half of the 20 th century and has been broadly applied since in multiple disciplines to model a wide array of new technologies, brands, and social innovations. For example, in the field of marketing in which hundreds of applications have been described, literature reviews and meta-analyses have been published to describe factors that influence adoptions of innovations $(1,2)$. The basic theory is simple and intuitive. Innovations diffuse into society following a logistic growth curve. Early demand for an innovation motivates additional future demand. Scholars identified two plausible and potentially complementary causal mechanisms for the observed trajectories: $(a)$ income distribution of the population, which affected who was able to assume the risks associated with new technologies, and $(b)$ a heterogeneous population in which certain people were more inclined to be early adopters than others (3). For example, although bicycling is not a new innovation, the income distribution and the heterogeneous population mechanisms of diffusion can be used to interpret how changes in levels of bicycling and the presence of bicyclists on the street have the potential to induce additional demand. Duesenberry's income distribution theory posited that the cost of an innovation fell 
with greater consumption, which enabled a larger segment of the population to afford it (3). For example, one major (unpriced) cost of bicycling is risk or the perception of risk. The visibility of cyclists changes driver behavior, which increases the safety for bicyclists (i.e., lowers the risk cost), which in turn increases the utility of bicycling for others (4-6). Jacobsen observed an inverse relationship between rates of bicycling and incidences of collision with motor vehicles across multiple cities, countries, and over time (6). He theorized that, as drivers saw more bicyclists on the street, they learned to anticipate the presence and behavior of bicyclists and to drive more cautiously. This outcome was consistent with Duesenberry's cost theory. As the number of bicyclists on the street increases, their visibility triggers greater acceptance and caution among drivers, which increases safety for bicyclists. Put another way, the cost (in terms of risk) falls as more people bike, so bicycling becomes accessible to new segments of the population.

In contrast to this more narrow economic interpretation, Rogers argued that innovations were diffused through heterogeneous populations on the basis of individual propensity to adopt new technologies (7). Rogers grouped the population into five categories on the basis of their adoption speed: innovators, early adopters, early majority, late majority, and laggards. Innovators and early adopters readily consume new technologies, while slower groups need to see the technology tested among their peers before they adopt it. With bicycling, this effect can be thought of as a social influence effect. As bicycling becomes increasingly visible, popular, and normalized, slower adoption groups become more comfortable with the idea of bicycling $(8,9)$. Evidence from the literature suggests that individuals' decisions to bike are influenced by their exposure to bicycling in their social network and around the city. Goetzke and Rave, for example, found a positive relationship between an individual's social network and a city's bicycle culture and an individual's propensity to bike for shopping and recreation trips in Germany (10).

\section{Bikeshare and Diffusion of Innovation Theory}

Bicycling is not a new mode of transportation, but bikeshare programs are new additions to transportation systems that have been made practical through the integration of innovations with information technology, which ranges from the Internet to improvements in credit card processing technology to GPS. Hence, the evolution of bikeshare programs can be interpreted within an innovation of diffusion framework. For any specific bikeshare program, an individual's decision to purchase a bikeshare membership and add bikeshare as a potential mode choice can be interpreted as commitment to, or adoption of, a distinctive brand of bicycling. The metaphor of a branda particular type of product with particular characteristics produced by a particular vendor or entrepreneur-is appropriate for bikeshare, given approaches used in marketing (e.g., the deployment of uniform, distinctly painted bicycles with particular features for safety and convenience). In addition, the rich data sets from bikeshare systems made possible by technological innovations make possible studies unique to this transportation alternative. Partly because of the growing prevalence of bikeshare systems and partly because these systems generate data that are publicly available for study, the number of studies of bikeshare systems recently has grown.

Fishman et al. synthesized the bikeshare literature in 2013 and reported, among other findings, that bikeshare members prioritized convenience and value, that bikeshare members were more likely than nonmembers to own and use their own bikes, and that bike- share users were more likely to substitute bikeshare for other sustainable modes of transportation than private vehicles (11). They observed that "the potential for bikeshare to act as a catalyst for private bike riding has received little attention" (11, p. 162). In an assessment of bikeshare systems in North America, Shaheen et al. observed that the bikeshare industry had yet to adopt a "dominant business model" and that diversity was great across programs in terms of funding sources and operations (12, p. 92).

Many studies of bikeshare systems have focused on membership, correlates of bikeshare use, and effects on mode choice. For example, Fishman et al. found that the home and work locations of nonbikeshare members in Brisbane and Melbourne, Australia, were more likely to be geographically dispersed than the home and work locations of bikeshare members (11). In related analyses, they found that survey respondents "aged 18-34 and having docking stations within $250 \mathrm{~m}$ of their workplace" were significantly more likely to be bikeshare members $(13$, p. 325$)$. In a comparison of bikeshare users in Washington, D.C., Buck et al. found that Capital Bikeshare members "were more likely to be female and younger, to have lower household incomes, and to own fewer cars and fewer bicycles, and were more likely to cycle for utilitarian purposes" (14, p. 112).

Wang et al. showed that bikeshare station activity (i.e., origins and arrivals) was associated with neighborhood sociodemographics, proximity to the central business district, proximity to water, accessibility to trails, distance to other bikeshare stations, and measures of economic activity (15). Rixey reported similar findings: population and job density, higher levels of income and education, presence of bikeways, and proximity to other stations were positively correlated with station use; nonwhite populations and adverse weather were negatively associated (16). With respect to the effects of bikeshare on other travel modes, Ma et al. studied the association between Capital Bikeshare and Washington, D.C.'s Metro rail system (17). They found that bikeshare activity within a transit station's catchment area was positively associated with transit ridership, and asserted a spillover effect, although the direction of causality in their findings was not clearly established. Fishman et al. estimated reductions in miles traveled associated with bikeshare use (18). Martin and Shaheen found that the effects of bikeshare on transit varied by location of residence and across cities. Specifically, they found that, in Washington, D.C., bikeshare participants that lived on the urban periphery shifted toward use of bus and rail, while residents of the urban core tended to use transit less (19). Conversely, in Minneapolis, they found that bikeshare member shifts toward rail included residents of the urban core, while modal shifts for buses were more dispersed.

More generally, Wang et al. studied neighborhood social effects on mode choice and found evidence of contagion, specifically, that "the more OSU-affiliated bicycle riders are residing around an individual OSU commuter, the more attractive bicycling becomes, controlling for other factors such as gender, status, proximity to campus, bicycle infrastructure and attitudes" (20, p. 122). In related studies, Efthymiou et al. reported factors associated with adopting vehicle sharing systems (21). Researchers also have explored public health externalities associated with nonmotorized transportation $(22,23)$.

With respect to bikeshare and diffusion of innovation theory, researchers have explored growth in the numbers of systems and used survey methods to assess the likelihood of individual adoption of bikeshare, but researchers have not modeled system membership growth or whether bikeshare affects bicycle mode choice generally. Parkes et al. studied the spread of bikeshare systems through Europe and North America (24). They found the number of systems in place 
over time followed an ess curve in Europe and, as of 2012, appeared to be approaching maturity. In North America, however, the curve appeared to still be in the "birth" or early "growth" phase. Therrien et al. studied bikeshare diffusion in Vancouver, British Columbia, Canada, at the individual level through a stated preference survey in which residents indicated how likely they would be to use a proposed bikeshare system (25). Their binary logistic regression model identified on the basis of self-reporting the characteristics of those likely to use the new system (controlling for socioeconomic and demographic attributes), and they stratified their sample on the basis of these characteristics into Rogers' categories of adopters (7). Fuller et al. studied the effects of the Société de Vélo en Libre-Service (i.e., Bixi) public bicycle-sharing system in Montreal, Quebec, Canada, on all types of bicycling and found that people exposed to the Bixi system were more likely to bike (26). The present study built on these applications of diffusion on innovation theory to introduce new models of membership growth and the effects of bikeshare on bicycle mode choice within a general population.

\section{METHODOLOGY}

\section{Theory and Hypotheses}

In Rogers' heterogeneous population diffusion of innovation framework, bikeshare systems (e.g., Nice Ride Minnesota, Minneapolis and Saint Paul; Capital Bikeshare, Washington, D.C.; and Divvy Bikeshare, Chicago, Illinois) can be thought of as distinctive brands of cycling (7). The Nice Ride bikes, for example, all are painted a bright lime-green, equipped with standard baskets, and operate with flashing front lights visible to oncoming traffic. Matching lime-green helmets are sold and often given away as promotions. Adoption of the brand depends on individual tendencies toward innovation and imitation and overall rates of adoption. The high visibility of bikeshare systems and bicycles suggests that bikeshare systems may have a distinct effect on further adoption of the system and cycling in general.

Equation 1 describes the probability of adopting an innovation $\left(b_{i}(t)\right)$ as a function of inclinations toward innovation $\left(p_{i}(t)\right)$ and imitation $\left(q_{i}(t)\right)$ and the proportion of adopters $(G(t))$ at time $t$, with use of the equation presented by Meade and Islam (3).

$b_{i}(t)=p_{i}+q_{i} G(t)$

Nice Ride, as a brand of bicycling, is highly visible. People whose exposure to Nice Ride users is high are expected to have an increased likelihood of bicycling, given the larger effects of imitation $\left(q_{i}\right)$. In other words, the probability that an individual adopts Nice Ride is a function of that person's tendency toward innovation (early adoption) and tendency to imitate peers, taking into account how many peers in fact use the brand (i.e., bicycling).

The study hypothesized that bikeshare systems had a spatial contagion or spillover effect as follows:

$H 1$. Propensity to become a Nice Ride member (i.e., potentially begin to use the bikeshare system) and

$H 2$. Propensity to bicycle among the general population.

Two models were estimated to test these hypotheses. For $H 1$, a parsimonious, lagged variable regression model was used to predict net bikeshare system membership change in a census block group as a function of prior bikeshare system membership levels, which controlled for system expansion locally (at nearby stations) and systemwide. A positive and significant coefficient on the prior bikeshare system membership would indicate a potential diffusion of innovation effect in which the presence of early bikeshare adopters influenced the decisions and behaviors of people around them. The membership models were restricted to measures of membership and system growth, because detailed data on individual members and data to measure changes in characteristics of areal units of analysis (i.e., census block groups) were not available for each year of the analysis. Costs were not included, because net changes were negligible in annual costs of membership for the years modeled.

For $H 2$, a household's propensity to bicycle and its frequency of bicycle trips were modeled as a function of bikeshare trips that started or ended near the household. Dedicated bicycle infrastructure and population density near the home location were controlled for and so were the sociodemographic characteristics of the household. A positive and significant coefficient on bikeshare trip activity would suggest a potential diffusion or spillover effect of bikeshare on general population cycling in which the visibility of a specific brand (bikeshare cycling activity) nearby changed an individual's own propensity to use the technology (any type of cycling).

\section{Data Sources}

Two main data sources were used: (a) trip and subscriber records from the local bikeshare system and $(b)$ regional travel behavior inventory survey data about general population households and daily trips (27-29).

The Nice Ride Minnesota bikeshare system in Minneapolis and Saint Paul was launched in 2010. Ridership increased steadily throughout the period analyzed, from 2010 (about 100,000 trips) through 2013 (more than 300,000 trips). Nice Ride Minnesota provided a database of subscribers and trips taken on the Nice Ride bikeshare system. The origin station, destination station, start time, end time, and subscriber ID were electronically recorded for every trip. For subscribers, the database contained the date a subscriber joined, age, geographic location, gender, and subscription type. Figure 1 shows the geocoded approximate locations of Nice Ride's subscribers. Walk-up day pass users were not included in the subscriber database or the map.

The regional planning agency (i.e., Metropolitan Council) administers a travel behavior inventory every decade, which includes travel diaries for all members of households that participate. Data from the 2011 travel behavior inventory were provided by the Metropolitan Council to explore the effects of Nice Ride on cycling among non-Nice Ride subscribers (general population). The travel behavior inventory surveyed 14,055 randomly selected households (about $1 \%$ ) in the Minneapolis-Saint Paul Metropolitan Region. Each resident over the age of 5 kept a 24-h diary with a record of all trips made by all modes. The survey was administered on weekdays from December 2010 to February 2012, including Nice Ride's 2011 season. The analysis included only Minneapolis households $(N=1,941)$ because of Nice Ride's limited presence in Saint Paul at that time.

Each household record contained the number of trips made by all members of the household, the number of bicycle trips, sociodemographic characteristics, and a set of spatial measures around the household (e.g., population density and availability of bicycle infrastructure near the home). These variables are defined in the next section. 


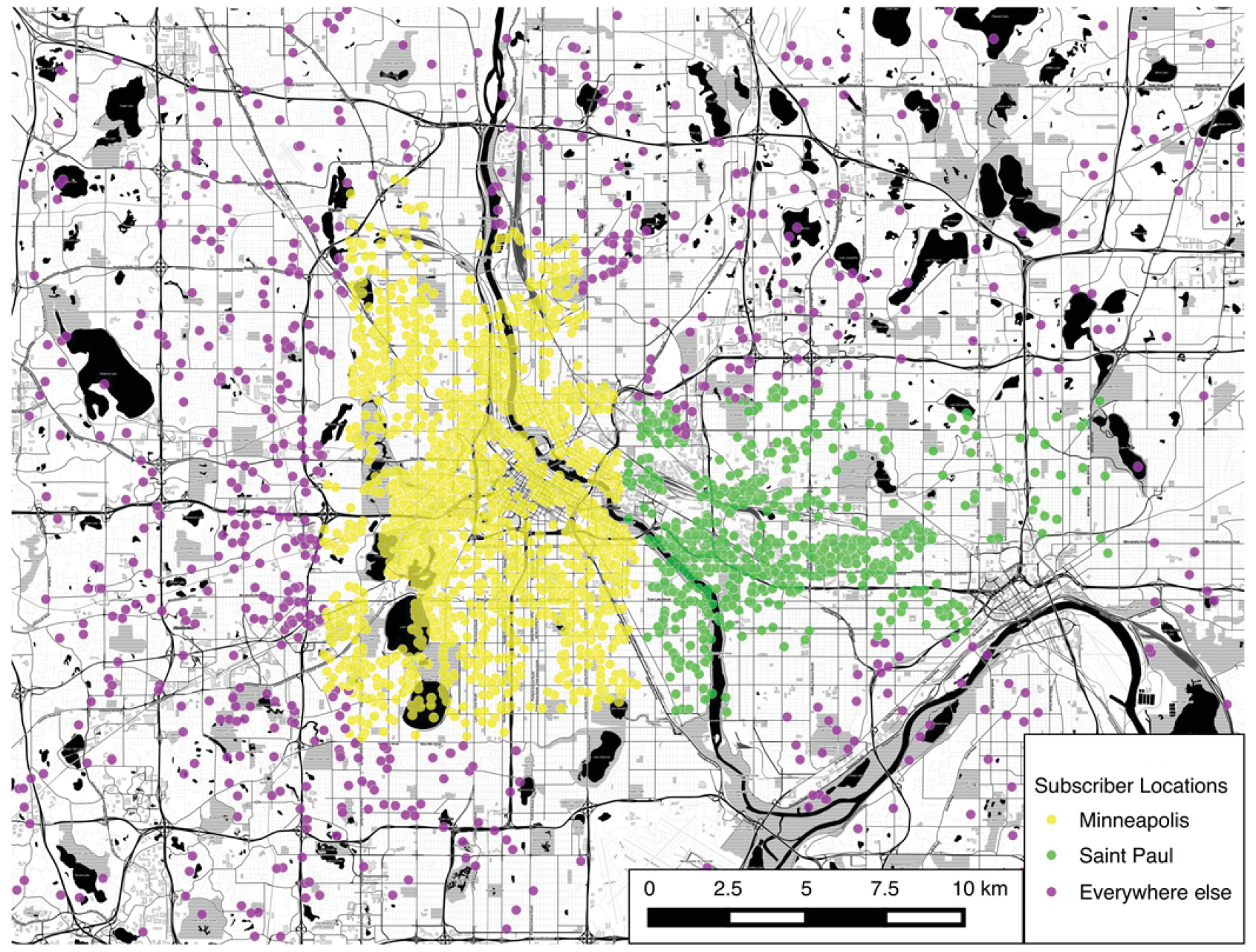

FIGURE 1 Map of Nice Ride Minnesota monthly, annual, and 30-day pay-as-you-go subscribers. (Source: Stamen Toner OSM.)

\section{Variables and Modeling}

This study included two main sets of models. One set tested $H 1$ : the effects of Nice Ride system membership on membership growth, while controlling for system growth; the other tested $H 2$ : effects of Nice Ride trip activity on household cycling participation and frequency among the general population.

\section{Nice Ride Membership Growth Model (H1)}

The effect of Nice Ride system membership on membership growth was analyzed with the use of a lagged variable linear model of net change in membership density on census block groups from the previous season as a function of the density of members in the previous season, controlling for local system growth and systemwide growth. Equations $2 a$ and $2 b$ show these relationships; definitions of variable symbols and descriptive statistics are presented in Table 1. Local growth was measured as net change in station density (i.e., number of stations per square kilometer) from the previous season. Systemwide growth was modeled in two ways: as an indicator variable for the current season, with the 2011 season as the base case (Equation 2a), or as the net change in number of stations systemwide from the previous season (Equation $2 b$ ). For example, there were 65 stations in 2010 and 116 stations in 2011, so the system growth variable for 2011 was $116-65=51$. The model was built with data from the 2010 through 2013 systems, and with 4,199 census block groups in the cities of Minneapolis and Saint Paul.

$\Delta m_{t_{0} \rightarrow t_{1}, i} \rightarrow f\left(m_{t_{0}, i}, \Delta s_{t_{0} \rightarrow t_{1}, i}, t_{1}\right)$

$\Delta m_{t_{0} \rightarrow t_{1}, i} \rightarrow f\left(m_{t_{0}, i}, \Delta s_{t_{0} \rightarrow t_{1}, i}, \Delta S_{t_{0} \rightarrow t_{1}, I}\right)$

where $t_{0}$ and $t_{i}$ are season binary indicators.

\section{General Population Cycling Model (H2)}

Households near Nice Ride stations, particularly Nice Ride stations with high levels of use, were hypothesized to have higher rates of participation in cycling (defined as any household member that made at least one trip by bicycle) and to have a higher frequency of bicycle trips than households not located near Nice Ride stations. The general population cycling model explored household participation in, and frequency of, bicycling. Participation was defined as any household member who reported making one or more bicycle trips on their assigned travel day. Frequency was the total number of bicycle trips made by all members of the household. Participation and frequency 
TABLE 1 Descriptive Statistics of Modeling Variables

\begin{tabular}{|c|c|c|c|c|c|c|}
\hline Variable & Description & $N$ & Mean & SD & Min. & Max. \\
\hline \multicolumn{7}{|c|}{ Hypothesis $H 1$-Model 1. Spillover Effects on System Membership ${ }^{a}$} \\
\hline$\overline{\Delta m_{t_{0} \rightarrow t_{1, i}}}$ & $\begin{array}{l}\text { Dependent variable: net subscribers per 1,000 residents from } \\
t_{0} \text { to } t_{1} \text { for block group } i\end{array}$ & 4,199 & 0.56 & 2.97 & -30.36 & 62.20 \\
\hline$m_{t_{0, i}}$ & Subscribers per 1,000 residents in $t_{0}$ for block group $i$ & 4,199 & 1.55 & 4.71 & 0.00 & 78.95 \\
\hline$\Delta s_{t_{0} \rightarrow t_{1, i}}$ & Net stations per $\mathrm{km}^{2}$ from $t_{0}$ to $t_{1}$ for block group $i$ & 4,199 & 0.06 & 0.87 & -23.02 & 23.02 \\
\hline$\Delta S_{t_{0} \rightarrow t_{1, l}}$ & Net stations from $t_{0}$ to $t_{1}$ for entire system $I$ & 4,199 & 35.00 & 11.43 & 25.00 & 51.00 \\
\hline \multicolumn{7}{|c|}{ Hypothesis $H 2-$ Model 2. Spillover Effects on General Population Cycling } \\
\hline$h_{b}$ & Dependent variable: household participation in cycling (binary) & 1,941 & 0.12 & 0.33 & 0.00 & 1.00 \\
\hline$h_{r b}$ & Dependent variable: number of household bike trips & 1,941 & 0.40 & 1.34 & 0.00 & 12.00 \\
\hline$s_{o d}$ & Number of Nice Ride trips within $400 \mathrm{~m}$ (thousands) ${ }^{b}$ & 1,941 & 0.86 & 2.46 & 0.00 & 15.34 \\
\hline$e_{k}$ & Population density within $400 \mathrm{~m}$ (people per acre) & 1,941 & 14.31 & 7.80 & 0.58 & 49.32 \\
\hline$e_{l}$ & $\mathrm{~km}$ of bike lanes within $400 \mathrm{~m}$ & 1,941 & 0.20 & 0.46 & 0.00 & 2.88 \\
\hline$e_{p}$ & $\mathrm{~km}$ of bike trails within $400 \mathrm{~m}$ & 1,941 & 0.11 & 0.23 & 0.00 & 1.82 \\
\hline$h_{r}$ & Number of trips by any mode ${ }^{c}$ & 1,941 & 7.81 & 5.36 & 1.00 & 37.00 \\
\hline$h_{w}$ & Number of workers & 1,941 & 1.04 & 0.81 & 0.00 & 4.00 \\
\hline$h_{u}$ & Student(s) (binary) & 1,941 & 0.22 & 0.42 & 0.00 & 1.00 \\
\hline$h_{c}$ & Child(ren) younger than 6 years (binary) & 1,941 & 0.08 & 0.28 & 0.00 & 1.00 \\
\hline
\end{tabular}

were modeled jointly with a zero-inflated negative binomial regression model. The explanatory variables included the number of Nice Ride bikeshare trips that started or ended within $400 \mathrm{~m}(1 / 4 \mathrm{mi})$ of the household, along with other sociodemographic and built environment variables, summarized in Table 1 . The researchers selected the number of Nice Ride trips that started or ended within $400 \mathrm{~m}$ as the key variable of interest. It was hypothesized that Nice Ride's visibility was the principal mechanism behind a potential spillover effect; other unobservable factors (e.g., personal contacts or relations) also may have been factors. Trip activity at a station implied visibility of the station itself and visibility of bicyclists that used Nice Ride on the streets around the station, whereas a simple measure of stations near the household was an incomplete measure of visibility. Given multicollinearity between Nice Ride measures, it was inappropriate to use multiple Nice Ride station and trip activity measures in the same model.

\section{RESULTS}

\section{Diffusion Effects on Expanding Membership}

Table 2 presents the findings for the parsimonious Models $1 \mathrm{~A}$ and $1 \mathrm{~B}$ of bikeshare membership on membership growth. The $R^{2}$-values for both models were approximately .07 , which meant that only $7 \%$ of the change in block group Nice Ride membership per 1,000 residents could be explained by system growth (new stations) and membership growth nearby. All variables in both models were significant. The coefficients for subscribers and increase in stations were nearly identical between the two models.

Table 3 shows the elasticities of each variable with other variables held at their means for Model 1B. The elasticities show that the systemwide growth variable had the largest effect on membership growth at the block group level, with a $1 \%$ change in the number of
TABLE 2 Ordinary Least Squares Regression Model of Spillover Effects on Membership Growth

\begin{tabular}{|c|c|c|c|c|}
\hline \multirow[b]{2}{*}{ Variable } & \multicolumn{2}{|c|}{$\begin{array}{l}\text { Model 1A } \\
\text { Seasonal Indicator } \\
\text { Variables }\end{array}$} & \multicolumn{2}{|c|}{$\begin{array}{l}\text { Model 1B } \\
\text { System Growth } \\
\text { Variable }\end{array}$} \\
\hline & Coefficient & SE & Coefficient & SE \\
\hline$m_{t_{0, i}}$ & $0.061 * * *$ & 0.010 & $0.061 * * *$ & 0.010 \\
\hline$\Delta s_{t_{0} \rightarrow t_{1, i}}$ & $0.300 * * *$ & 0.052 & $0.300 * * *$ & 0.052 \\
\hline$t_{1}=2011$ & \multicolumn{2}{|c|}{ (Base case) } & \multicolumn{2}{|c|}{ (Base case) } \\
\hline$t_{1}=2012$ & $-1.353^{* * *}$ & 0.110 & na & na \\
\hline$t_{1}=2013$ & $-1.681 * * *$ & 0.111 & na & na \\
\hline$\Delta s_{t_{0} \rightarrow t_{1, I}}$ & na & na & $0.064 * * *$ & 0.004 \\
\hline Constant & $1.456^{* * *}$ & 0.078 & $-1.781 * * *$ & 0.149 \\
\hline$R^{2}$-value & \multicolumn{2}{|c|}{.0714} & \multicolumn{2}{|c|}{.0713} \\
\hline
\end{tabular}

NoTE: na $=$ not applicable

*** Significant at $p<.01$; **significant at $p<.05$; *significant at $p<.10$.

TABLE 3 Marginal Effects of Model 1B Variables on Membership

\begin{tabular}{lcc}
\hline Change in Variable & $\begin{array}{l}\text { Change }(\%) \\
\text { in } \Delta m_{t_{0} \rightarrow t_{1, i}} \\
(e y / e x)^{a}\end{array}$ & $\begin{array}{l}\text { Numeric Change } \\
\text { in } \Delta m_{t_{0} \rightarrow t_{1, i}} \\
(d y / e x)^{b}\end{array}$ \\
\hline $1 \%$ change in $m_{t_{0, i}}$ & 0.170 & 0.095 \\
$1 \%$ change in $\Delta s_{t_{0} \rightarrow t_{1, i}}$ & 0.033 & 0.019 \\
$1 \%$ change in $\Delta s_{t_{0} \rightarrow t_{1, i}}$ & 3.990 & 2.226 \\
\hline
\end{tabular}

NOTE: Elasticities calculated with other variables held at means. ${ }^{a}$ ey/ex $=$ percentage change in outcome for a $1 \%$ change in independent variable.

${ }^{b} d y / e x=$ unit change in outcome for a 1-unit change in independent variable. 
new stations across the system added and associated with an almost $4 \%$ change in membership growth, or 2.2 additional new members in a block group. With the systemwide new station variable held at its mean, each $1 \%$ increase in stations per kilometer in a block group was associated with 0.02 additional new members. A $1 \%$ increase in the base year's members per 1,000 residents was associated with 0.1 additional new members in the following season, which suggested only a modest spillover effect of membership on future membership.

\section{Spillover Effects on General Population Cycling}

Table 4 presents the results from three models of bicycling participation and frequency. The binary logistic regression of participation in cycling had the highest pseudo- $R^{2}$-value, at .0810. Although the McFadden pseudo- $R^{2}$-value does not have the same interpretation as $R^{2}$-value in linear regression, this result still indicated that bicycling was not well explained by this set of variables. The $\alpha$ parameter was significant in all three models, which suggested that the dependent variable $h_{r b}$ was overdispersed, and negative binomial regression was appropriate (Table 4). In addition, a Vuong test that compared the zero-inflated models with standard negative binomial regression was significant at the $p<.01$ level (not shown).

The variable of interest [i.e., the number of Nice Ride trips that started and ended near a household $\left.\left(s_{o d}\right)\right]$, was not significant in any of the models. This analysis did not find evidence of a spillover effect of Nice Ride on household participation in, and frequency of, bicycling. The results of additional models, which used the number of stations within $400 \mathrm{~m}$ instead of trip activity, were insignificant also.

Several other variables were significant in the models, however. Population density was positive and significant in all three models (participation equation only in Model 2C). Bike paths or trails within $400 \mathrm{~m}$ of home were positively associated with participation in cycling (Models 2A and 2C). In addition, the household structure (e.g., number of workers, presence of students, overall number of trips made) was associated with participation and frequency.

\section{DISCUSSION OF RESULTS}

This research showed a potential diffusion or spillover effect of existing bikeshare members on future system adoption and membership growth. The effect was modest but significant: for a census

TABLE 4 Models of Spillover Effects on General Population Cycling Participation and Frequency

\begin{tabular}{|c|c|c|c|c|c|c|}
\hline \multirow[b]{2}{*}{ Equation } & \multicolumn{2}{|c|}{$\begin{array}{l}\text { Model 2A } \\
\text { Binary Logit Model } \\
\text { of Participation }\end{array}$} & \multicolumn{2}{|c|}{$\begin{array}{l}\text { Model 2B } \\
\text { Negative Binomial } \\
\text { Model of Frequency }\end{array}$} & \multicolumn{2}{|c|}{$\begin{array}{l}\text { Model 2C } \\
\text { Zero-Inflated } \\
\text { Negative Binomial } \\
\text { Model of Participation } \\
\text { and Frequency }\end{array}$} \\
\hline & Coefficient & SE & Coefficient & SE & Coefficient & SE \\
\hline \multicolumn{7}{|l|}{ Participation } \\
\hline$s_{o d}$ & -0.045 & 0.041 & na & na & -0.051 & 0.042 \\
\hline$e_{k}$ & $0.047 * * *$ & 0.010 & na & na & $0.045^{* * *}$ & 0.010 \\
\hline$e_{l}$ & -0.180 & 0.197 & na & na & -0.185 & 0.205 \\
\hline$e_{p}$ & $0.606^{* *}$ & 0.302 & na & na & $0.741 * *$ & 0.332 \\
\hline$h_{r}$ & $0.076^{* * *}$ & 0.014 & na & na & $0.067 * * *$ & 0.015 \\
\hline$h_{w}$ & $0.392 * * *$ & 0.098 & na & na & $0.453 * * *$ & 0.104 \\
\hline$h_{u}$ & $0.313^{*}$ & 0.175 & na & na & 0.282 & 0.182 \\
\hline$h_{c}$ & 0.006 & 0.233 & na & na & 0.063 & 0.248 \\
\hline Constant & $-3.897 * * *$ & 0.244 & na & na & $-3.714 * * *$ & 0.256 \\
\hline \multicolumn{7}{|l|}{ Frequency } \\
\hline$s_{o d}$ & na & na & -0.026 & 0.040 & 0.022 & 0.025 \\
\hline$e_{k}$ & na & na & $0.050 * * *$ & 0.012 & 0.010 & 0.007 \\
\hline$e_{l}$ & na & na & -0.104 & 0.236 & 0.007 & 0.146 \\
\hline$e_{p}$ & na & na & 0.277 & 0.394 & -0.351 & 0.237 \\
\hline$h_{r}$ & na & na & $0.123 * * *$ & 0.021 & $0.044 * * *$ & 0.010 \\
\hline$h_{w}$ & na & na & $0.227^{*}$ & 0.123 & $-0.183 * *$ & 0.075 \\
\hline$h_{u}$ & na & na & 0.334 & 0.218 & 0.134 & 0.117 \\
\hline$h_{c}$ & na & na & -0.222 & 0.318 & -0.192 & 0.162 \\
\hline Constant & na & na & $-3.206^{* * * *}$ & 0.293 & $0.657 * * *$ & 0.188 \\
\hline $\ln (\alpha)$ & na & na & $2.369 * * *$ & 0.096 & $-1.754 * * *$ & 0.328 \\
\hline $\begin{array}{l}\text { McFadden } \\
\text { pseudo- } R^{2}\end{array}$ & \multicolumn{2}{|c|}{.0810} & \multicolumn{2}{|c|}{.0353} & \multicolumn{2}{|c|}{.0650} \\
\hline
\end{tabular}

$* * *$ Significant at $p<.01 ; * *$ significant at $p<.05$; *significant at $p<.10$. 
block group with 1,000 residents and a base-year membership of 100 residents, Model 1B predicted that one new member would join, while it controlled for station density and overall system growth. However, the effect was not apparent when the research was generalized: no evidence of spillover effects of bikeshare was found on the propensity to cycle within the general population. It was concluded that the hypothesis that growth in bikeshare membership may be associated spatially with existing bikeshare membership warrants further study. This effect was assessed with parsimonious models that included only the effects of prior, proximate membership and stations. Specifically, it would be useful to develop new data sets with individual-level data to test similar hypotheses and expand the use of control variables.

This study also hypothesized that bikeshare trip activity would increase propensity to cycle among people nearby, because Nice Ride's presence was particularly visible. The fact that no associate was observed does not mean, however, that none existed. It is possible, for example, that the bikeshare system may have been too young or too small a component in the transportation system overall to have a measurable effect at this time. The Nice Ride Minnesota bikeshare system opened in 2010, which limited the data available to three lagged periods (i.e., 2010 to 2011, 2011 to 2012, 2012 to 2013). Bicycling comprises only a small percentage of trips made in Minneapolis and Saint Paul, with slightly fewer than 90,000 bicycle trips per day between the two cities (or 5\% and $2 \%$ mode shares, respectively) (18). In comparison, only about 217,000 Nice Ride trips were made during the entire 2011 season (from April to November), or about 1,000 trips per day-a tiny percentage of an already small mode share. That bikeshare membership has spillover effects on future members suggests potential for broader spillover effects as systems mature. As bikeshare systems worldwide continue to expand, and existing systems continue to grow and mature, new opportunities for future research into spillover effects on larger, more established systems will be available. Additional studies would be useful that integrated bikeshare data with the results of population-based travel behavior models.

The findings of this present study, especially the significant effect of existing membership on membership growth, have several implications for policy. Although the overall systemwide growth variable had the largest effect on membership growth in Model 1B, existing membership levels in a block group had a larger effect than local system growth. Bikeshare organizations may be able to harness this energy through "Take your friend on a bike ride" types of marketing schemes. Unless and until future research shows otherwise, however, bikeshare systems should not be treated as a substitute for other infrastructure improvements (e.g., provision of safe facilities) that increase the propensity to cycle.

The study design and findings also provide a foundation for new research into bikeshare diffusion of innovation effects. As bikeshare systems continue to emerge and evolve throughout the world, so too will new sources of bikeshare data and opportunities to explore these relationships. This present research had several notable limitations that invite further inquiry into the topic. The travel behavior inventory was administered after Nice Ride had been operational only for one season. Nice Ride's largest system expansion after the initial investment occurred over the second season, which coincided with light rail construction in many of the areas that received new stations. Small segments of the population, such as cyclists, are difficult to represent in general population surveys administered to a low percentage of the population. Preliminary models, which controlled for weather, did not produce different results in the house- hold bicycling participation and frequency models (not shown in the final model). Nonetheless, weather is always a concern in research on nonmotorized travel in extreme climates such as Minnesota's.

\section{ACKNOWLEDGMENTS}

The authors acknowledge the Center for Prevention at Blue Cross and Blue Shield of Minnesota, the Metropolitan Council, and Nice Ride Minnesota for support of the original studies on which this research is based.

\section{REFERENCES}

1. Mahajan, V., E. Muller, and F. Bass. New Product Diffusion Models in Marketing: A Review and Directions for Research. Journal of Marketing, Vol. 54, No. 1, 1990, pp. 1-26.

2. Sultan, F., J. Farley, and D. Lehmann. A Meta-Analysis of Applications of Diffusion Models. Journal of Marketing Research, Vol. 27, No. 1, 1990, pp. 70-77.

3. Meade, N., and T. Islam. Modelling and Forecasting the Diffusion of Innovation-A 25-Year Review. International Journal of Forecasting, Vol. 22, No. 3, 2006, pp. 519-545. http://linkinghub.elsevier.com/retrieve /pii/S0169207006000197. Accessed March 22, 2014.

4. Walker, I. Drivers Overtaking Bicyclists: Objective Data on the Effects of Riding Position, Helmet Use, Vehicle Type and Apparent Gender. Accident Analysis and Prevention, Vol. 39, 2007, pp. 417-425.

5. Walker, I., I. Garrard, and F. Jowitt. The Influence of a Bicycle Commuter's Appearance on Drivers Overtaking Proximities: An On-Road Test of Bicyclist Stereotypes, High-Visibility Clothing and Safety Aids in the United Kingdom. Accident Analysis and Prevention, Vol. 64, 2014, pp. 69-77. http://dx.doi.org/10.1016/j.aap.2013.11.007.

6. Jacobsen, P.L. Safety in Numbers: More Walkers and Bicyclists, Safer Walking and Bicycling. Injury Prevention, Vol. 9, No. 3, 2003 pp. 205-209. http://www.pubmedcentral.nih.gov/articlerender.fcgi ?artid $=1731007 \&$ tool $=$ pmcentrez \&rendertype $=$ abstract.

7. Rogers, E. M. Diffusion of Innovations. Free Press of Glencoe, New York, 1962.

8. Aldred, R., and K. Jungnickel. Why Culture Matters for Transport Policy: The Case of Cycling in the UK. Journal of Transport Geography, Vol. 34, 2014, pp. 78-87. http://dx.doi.org/10.1016/j.jtrangeo.2013.11.004.

9. Heinen, E., and S. Handy. Similarities in Attitudes and Norms and the Effect on Bicycle Commuting: Evidence from the Bicycle Cities Davis and Delft. International Journal of Sustainable Transportation, Vol. 6 , 2012, pp. 257-281.

10. Goetzke, F., and T. Rave. Bicycle Use in Germany: Explaining Differences Between Municipalities with Social Network Effects. Urban Studies, Vol. 48, No. 2, 2010, pp. 427-437. http://usj.sagepub.com/cgi /doi/10.1177/0042098009360681. Accessed Feb. 9, 2014.

11. Fishman, E., S. Washington, and N. Haworth. Bikeshare: A Synthesis of the Literature. Transport Reviews, Vol. 33, No. 2, 2013, pp. 148-165. http://dx.doi.org/10.1080/01441647.2013.775612.

12. Shaheen, S.A., A.P. Cohen, and E.W. Martin. Public Bikesharing in North America: Early Operator Understanding and Emerging Trends. In Transportation Research Record: Journal of the Transportation Research Board, No. 2387, Transportation Research Board of the National Academies, Washington, D.C., 2013, pp. 83-92.

13. Fishman, E., S. Washington, N. Haworth, and A. Mazzei. Barriers to Bikesharing: An Analysis from Melbourne and Brisbane. Journal of Transport Geography, Vol. 41, 2014, pp. 325-337.

14. Buck, D., R. Buehler, P. Happ, B. Rawls, P. Chung, and N. Boreck. Are Bikeshare Users Different from Regular Cyclists? A First Look at ShortTerm Users, Annual Members, and Area Cyclists in the Washington, D.C., Region. In Transportation Research Record: Journal of the Transportation Research Board, No. 2387, Transportation Research Board of the National Academies, Washington, D.C., 2013, pp. 112-119.

15. Wang, X., G. Lindsey, J. Schoner, and A. Harrison. Modeling Bikeshare Station Activity: Effects of Nearby Businesses and Jobs on Trips to and from Stations. Journal of Urban Planning and Development, Vol. 142, No. 1, 2015. 
16. Rixey, R.A. Station-Level Forecasting of Bikesharing Ridership: Station Network Effects in Three U.S. Systems. In Transportation Research Record: Journal of the Transportation Research Board, No. 2387, Transportation Research Board of the National Academies, Washington, D.C., 2013, pp. 46-55.

17. Ma, T., C. Liu, and S. Erdoğan. Bicycle Sharing and Public Transit: Does Capital Bikeshare Affect Metrorail Ridership in Washington, D.C.? In Transportation Research Record: Journal of the Transportation Research Board, No. 2534, Transportation Research Board, Washington, D.C., 2015, pp. 1-9.

18. Fishman, E., S. Washington, N. Haworth, and A. Watson. Factors Influencing Bikeshare Membership: An Analysis of Melbourne and Brisbane. Transportation Research Part A, No. 71, 2015, pp. 17-30.

19. Martin, E., and S. Shaheen. Evaluating Public Transit Modal Shift Dynamics in Response to Bikesharing: A Tale of Two U.S. Cities. Journal of Transport Geography, Vol. 41, 2014, pp. 315-324.

20. Wang, C.-H., G. Akar, and J.-M. Guldmann. Do Your Neighbors Affect Your Mode Choice? A Spatial Probit Model for Commuting to the Ohio State University. Journal of Transport Geography, Vol. 42, 2013, pp. 122-130. http://dx.doi.org/10.1016/j.jtrangeo.2014.12.003.

21. Efthymiou, D., C. Antoniou, and P. Waddell. Factors Affecting the Adoption of Vehicle Sharing Systems By Young Drivers. Transport Policy, Vol. 29, 2013, pp. 64-73. http://linkinghub.elsevier.com/retrieve /pii/S0967070X13000607. Accessed March 20, 2014

22. Fuller, D., L. Gauvin, A.-S. Dubé, M. Winters, K. Teschke, E. T. Russo, A. Camden, C. Mee, and S. M. Friedman. Evaluating the Impact of Environmental Interventions Across 2 Countries: the International Bikeshare Impacts on Cycling and Collisions Study (IBICCS) Protocol. BMC Public Health, Vol. 14, 2014. http://www.biomedcentral .com/1471-2458/14/1103.

23. Chatterjee, K., H. Sherwin, and J. Jain. Triggers for Changes in Cycling: The Role of Life Events and Modifications to the External Environment. Journal of Transport Geography, Vol. 30, 2013, pp. 183-193. http://
linkinghub.elsevier.com/retrieve/pii/S0966692313000215. Accessed Oct. 22, 2013.

24. Parkes, S. D., G. Marsden, S.A. Shaheen, and A.P. Cohen. Understanding the Diffusion of Public Bikesharing Systems: Evidence from Europe and North America. Journal of Transport Geography, Vol. 31, 2013, pp. 94-103. http://linkinghub.elsevier.com/retrieve/pii /S0966692313001130. Accessed March 21, 2014.

25. Therrien, S., M. Brauer, D. Fuller, L. Gauvin, K. Teschke, and M. Winters. Identifying the Leaders: Applying Diffusion of Innovation Theory to Use of Public Bikeshare System in Vancouver, Canada. In Transportation Research Record: Journal of the Transportation Research Board, No. 2468, Transportation Research Board of the National Academies, Washington, D.C., 2014, pp. 74-83.

26. Fuller, D., L. Gauvin, Y. Kestens, M. Daniel, M. Fournier, P. Morency, and L. Drouin. Impact Evaluation of a Public Bicycle Share Program on Cycling: A Case Example of BIXI in Montreal, Quebec. American Journal of Public Health, Vol. 103, No. 3, 2013, pp. e85-92. http:// www.ncbi.nlm.nih.gov/pubmed/23327280. Accessed May 31, 2013.

27. Schoner, J. E., R. A. Harrison, X. Wang, and G. Lindsey. Sharing to Grow: Economic Activity Associated with Nice Ride Bikeshare Stations. Hubert H. Humphrey School of Public Affairs, University of Minnesota, Minneapolis, 2012.

28. Schoner, J.E.T., G. Lindsey, and D. M. Levinson. Task 7 Technical Report. Biking and Walking Over Time. Minneapolis, Minn., 2015.

29. Schoner, J., and G. Lindsey. Differences Between Walking and Bicycling over Time: Implications for Performance Management. In Transportation Research Record: Journal of the Transportation Research Board, No. 2519, Transportation Research Board, Washington, D.C., 2015, pp. 116-127.

The authors are responsible for the analyses and opinions expressed in this paper.

The Standing Committee on Bicycle Transportation peer-reviewed this paper 